\title{
Localised subduction of anthropogenic carbon dioxide in the Southern Hemisphere oceans
}

Jean-Baptiste Sallée, ${ }^{\mathrm{a}}$, Richard J. Matear ${ }^{\mathrm{b}}$, Stephen R. Rintoul ${ }^{\mathrm{b}, \mathrm{c}}$, Andrew Lenton ${ }^{\mathrm{b}}$

${ }^{a}$ British Antarctic Survey

${ }^{b}$ CSIRO Marine and Atmospheric Research, Wealth from Oceans National Research Flagship

${ }^{c}$ Antarctic Climate and Ecosystems Cooperative Research Centre

Email address: jbsallee@gmail.com (Jean-Baptiste Sallée) 
The oceans slow the rate of climate change by absorbing about $25 \%$ of the annual anthropogenic $\mathrm{CO}_{2}$ emissions. The Southern Ocean makes a substantial contribution to this oceanic sink: more than $40 \%$ of the global oceanic inventory of anthropogenic $\mathrm{CO}_{2}$ has entered the ocean south of $40^{\circ} \mathrm{S}$. The rate-limiting step in ocean sequestration of anthropogenic $\mathrm{CO}_{2}$ is the transfer of carbon across the base of the surface mixed layer into the ocean interior, a process known as subduction. However, the physical mechanisms responsible for the subduction of anthropogenic $\mathrm{CO}_{2}$ are poorly quantified. Here we use observations to estimate a net subduction of $0.42 \pm 0.2 \mathrm{Pg} \mathrm{C}^{-1}$ between $35^{\circ} \mathrm{S}$ and the marginal sea-ice zone, and show that subduction occurs in specific locations when wind-driven Ekman transport, eddy fluxes and variations in mixed layer depth along mean streamlines subduct anthropogenic $\mathrm{CO}_{2}$. Both the magnitude and location of the estimated subduction have zonal asymmetries that are consistent with estimates of the interior distribution of anthropogenic $\mathrm{CO}_{2}$. Our results highlight the dependence of ocean carbon sequestration on physical properties sensitive to climate variability and change, including mixed layer depth, ocean currents, wind and eddies. 
Atmospheric $\mathrm{CO}_{2}$ continues to rise at unprecedented rates in response to human activities ${ }^{1}$. At present, the oceans take up more than $25 \%$ of anthropogenic $\mathrm{CO}_{2}$ $\left(\mathrm{C}_{\text {ant }}\right)$ emissions, thereby slowing the growth of atmospheric $\mathrm{CO}_{2}$ and the rate of climate change ${ }^{2}$. The rate-limiting step for ocean sequestration of $\mathrm{C}_{\text {ant }}$ is the transfer from the surface ocean to the ocean interior ${ }^{3,4,5}$. Knowledge of the mechanisms responsible for the transfer of $\mathrm{C}_{\text {ant }}$ between the well-ventilated surface mixed layer and the ocean interior, and their sensitivity to change, is key to understanding past, present and future carbon uptake by the ocean. However, both the pathways and rate by which $\mathrm{C}_{a n t}$ is sequestered in the ocean interior remain uncertain. No direct observations of the pathways and rates of anthropogenic carbon sequestration have been made, and consequently our present understanding is based on the interior distribution of $\mathrm{C}_{a n t}{ }^{6}$ or inferred from model simulations ${ }^{7}$.

The Southern Ocean is a particularly important region for the uptake and storage of $\mathrm{C}_{a n t}{ }^{8,9}$. The latitude band between $30^{\circ} \mathrm{S}$ and $50^{\circ} \mathrm{S}$ stores more $\mathrm{C}_{a n t}$ than any other latitude band in the ocean ${ }^{6}$. The efficient uptake and storage of $\mathrm{C}_{a n t}$ by the Southern Ocean is a result of the vigorous overturning circulation at high southern latitudes, in which water masses are formed and subducted into the ocean interior ${ }^{10}$. As water masses sink from the sea surface, they carry $\mathrm{C}_{\text {ant }}$ into the ocean interior. Subantarctic Mode Water (SAMW) and Antarctic Intermediate water (AAIW) formed on the northern flank of the Antarctic Circumpolar Current make the largest contribution to the uptake and storage of $\mathrm{C}_{a n t}$ by the Southern Ocean ${ }^{11,6,12}$.

Previous studies of the Southern Ocean $\mathrm{C}_{a n t}$ budget have focussed on air-sea fluxes and vertical transfer by Ekman pumping, with other physical processes transporting $\mathrm{C}_{\text {ant }}$ into (and out of) the ocean interior either simplified or neglected ${ }^{13,14,15,16}$. Three physical processes contribute to the transfer of fluid between the surface mixed layer and the interior ocean: wind-driven Ekman pumping, eddy fluxes and lateral induction by the mean flow. Until recently, the contribution of eddies and the mean flow to subduction could not be estimated from the available observations. The broad-scale, year-round sampling of the Southern Ocean by Argo floats means that this is now possible ${ }^{17}$ (see Methods). Here we show that $\mathrm{C}_{\text {ant }}$ leaves the ventilated surface layer of the Southern Ocean through localised maxima of subduction, and 
identify the physical mechanisms responsible.

\section{Mechanism and distribution of anthropogenic carbon subduction}

Our study considers the region between $35^{\circ} \mathrm{S}$ and the northern limit of the Antarctic winter sea ice $\left(\approx 65^{\circ} \mathrm{S}\right)$, for which there is good Argo coverage. We use recent observationally-based estimates of subduction ${ }^{17}$ and $\mathrm{C}_{\text {ant }}{ }^{18}$ in and at the base of the winter mixed layer (Figure 1a) to calculate the total subduction of $\mathrm{C}_{\text {ant }}$ from the mixed layer into the ocean interior in the 1990s. We quantify the individual contributions of Ekman divergence, eddy fluxes and the mean flow to subduction (see Methods).

Ekman transport leads to more or less zonally-uniform subduction of $\mathrm{C}_{\text {ant }}$ north of the ACC and re-ventilation (transport of $\mathrm{C}_{a n t}$ from below the mixed layer into the mixed layer) south of the ACC (Figure 1b). The eddy contribution mostly compensates the Ekman transport, with subduction in and south of the ACC and re-ventilation to the north (Figure 1d). The mean flow subducts fluid into the interior where the mixed layer shoals along the direction of the surface flow (streamlines) and re-ventilates fluid where the mixed layer deepens in the direction of the flow, a process known as lateral induction (see Supplementary Material). The mean flow largely determines the regional pattern of subduction and re-ventilation which varies strongly from region to region (Figure 1c). The total transport shows regions of both subduction and re-ventilation in all three basins (Figure 1e).

Our calculation gives a total of $0.42 \pm 0.2 \mathrm{PgC} / \mathrm{y}$ of $\mathrm{C}_{a n t}$ subducted into the Southern Ocean interior. Zonally-averaged, most subduction of $\mathrm{C}_{\text {ant }}$ occurs to the north of the ACC $(0.24 \pm 0.12 \mathrm{Pg} \mathrm{C} / \mathrm{y}$, Table 1$)$, reflecting the strong subduction by Ekman transport, partially offset by the eddy fluxes and mean flow. South of the ACC, the re-ventilation of $\mathrm{C}_{\text {ant }}$ by the Ekman transport is counter-balanced by subduction induced by eddy transport.

Importantly, the zonal averages hide the fact that $\mathrm{C}_{a n t}$ is both subducted and re-ventilated in the Southern Ocean. The largest re-ventilation occurs in the Indian Ocean sector, in a band extending eastward from South Africa to the middle of the basin. Maxima in re-ventilation also occur in the Pacific, east of New Zealand, and in 
the Atlantic, east of South America. Each of these maxima correspond to locations where the outflow from subtropical western boundary currents merges with the ACC and the mixed layer deepens along the direction of the mean flow (streamlines in Figure 1; see Supplementary Material).

In the re-ventilation regions, previously subducted $\mathrm{C}_{\text {ant }}$ is returned to the surface mixed layer. The return of the $\mathrm{C}_{\text {ant }}$ to the surface mixed layer reduces the efficiency of $\mathrm{C}_{\text {ant }}$ uptake by the Southern Ocean. Importantly, re-ventilation alters the pathways by which $\mathrm{C}_{\text {ant }}$ is transported from the surface mixed layer into the ocean. The connection between subduction and re-ventilation regions can be either local or remote. If the re-ventilation region is located directly downstream of the subduction region, and in the same density range, there is little net $\mathrm{C}_{a n t}$ transport into the ocean. For example, in the western Indian sector a strong re-ventilation region $\left(40^{\circ} \mathrm{E}-90^{\circ} \mathrm{E}\right)$ lies downstream of a strong subduction region $\left(0^{\circ} \mathrm{E}-60^{\circ} \mathrm{E}\right)$, resulting in weak net subduction (Figure 1e). The Indian section has regions of strong subduction and re-ventilation and overall has net subduction of $\mathrm{C}_{\text {ant }}(0.10$ $\mathrm{Pg} \mathrm{C} / \mathrm{y}$, Table 1). The net subduction of $\mathrm{C}_{\text {ant }}$ is slightly stronger in the Pacific (0.18 $\mathrm{Pg} \mathrm{C} / \mathrm{y}$ ) and Atlantic (0.13 Pg C/y) sectors of the Southern Ocean (Table 1).

The error estimates of the $\mathrm{C}_{a n t}$ transports are mainly due to the uncertainty in the $\mathrm{C}_{\text {ant }}$ concentrations. The $\mathrm{C}_{\text {ant }}$ concentrations used in this study are empirically derived estimates from measured in situ water properties ${ }^{19}$ and then mapped to a uniform grid $^{18}$. The $\mathrm{C}_{\text {ant }}$ concentration estimate has substantial uncertainties $^{20}$ because it requires extracting the small anthropogenic carbon signal from the much larger measured total dissolved inorganic carbon concentration. This substantial uncertainty is particularly large for the Southern Ocean ${ }^{9}$, where estimates of $\mathrm{C}_{\text {ant }}$ diverge even when applied to the same data ${ }^{21,22,23}$. The $\mathrm{C}_{\text {ant }}$ concentrations used here are likely uncertain by up to $\pm 40 \%$ reflecting uncertainties in estimating $\mathrm{C}_{\text {ant }}{ }^{20}$ and uncertainties due to mapping the concentrations to a uniform grid ${ }^{18}$ (see Supplementary Material).

While the uncertainty in $\mathrm{C}_{a n t}$ concentration influences the magnitude of the net transport of $\mathrm{C}_{a n t}$ into the ocean interior, it has no impact on the spatial distribution of the subduction and re-ventilation areas as these are set by the physical transport. 
Further, the regional distribution of subduction and re-ventilation sets the pathways by which $\mathrm{C}_{\text {ant }}$ is transferred from the mixed layer into the ocean interior. We next show that the inferred pathways are consistent with the regional pattern of $\mathrm{C}_{a n t}$ in the ocean interior.

\section{Surface to interior pathways}

For effective sequestration, $\mathrm{C}_{\text {ant }}$ subducted across the base of the mixed layer must be transported into the ocean interior, away from re-ventilation regions where $\mathrm{C}_{\text {ant }}$ can be returned to the mixed layer. The transport into the interior is accomplished by advection and mixing, primarily along isopycnal surfaces. While isopycnal mixing has a significant impact on transport in the ocean interior ${ }^{24}$, its contribution to subduction is negligible because it only acts at the base of the ventilated surface layer (see Methods). The inventory of $\mathrm{C}_{a n t}$ in the thermocline should therefore reflect the regional distribution of subduction and the isopyncal transport of $\mathrm{C}_{a n t}$ in the ocean interior.

The distribution of $\mathrm{C}_{\text {ant }}$ in the ocean interior is consistent with this hypothesis (Figure 2). Maxima in the observed inventory of $\mathrm{C}_{\text {ant }}$ occur in regions of strong net subduction and spread equatorward along streamlines into the ocean interior. For example, significant amounts of $\mathrm{C}_{a n t}$ are found on the $\sigma_{\theta}=26.8$ surface in the Indian Ocean, spreading equatorward along mean streamlines from the strong subduction region in the southeastern part of the basin, which is consistent with the distribution of potential vorticity ${ }^{17}$. Similarly, significant inventories of $\mathrm{C}_{\text {ant }}$ are found in the Pacific on the $\sigma_{\theta}=27.0$ surface and in the Atlantic on the $\sigma_{\theta}=$ 27.2 surface. $\mathrm{C}_{\text {ant }}$ is injected on the $\sigma_{\theta}=27.1$ surface near the Drake Passage and spreads into both the Pacific and Atlantic basins. The strong regional variations in the oceanic inventory of $\mathrm{C}_{\text {ant }}$ reflect the distribution of subduction "hot spots" and the circulation patterns linking these subduction regions with the ocean interior.

The inventory of $\mathrm{C}_{a n t}$ in density layers at $30^{\circ} \mathrm{S}$ reveals the dominant pathways by which $\mathrm{C}_{\text {ant }}$ is exported from the Southern Ocean to the subtropical gyres (Figure $3)$. In the lightest density classes $\left(\sigma_{\theta}=26.7-26.9\right)$, most of the $\mathrm{C}_{a n t}$ inventory is located in the Indian Ocean, particularly east of $60^{\circ} \mathrm{E}$, consistent with our estimated 
transport through the base of the surface layer (Figure 2a,b). Between $\sigma_{\theta}=26.9$ and 27.1, the Pacific makes the dominant contribution to the inventory of $\mathrm{C}_{a n t}$, with the largest values in the central basin (Figure 2). The Atlantic sequesters the greatest amount of $\mathrm{C}_{a n t}$ in the density range of the Antarctic Intermediate Water $\left(\sigma_{\theta}=27.0-27.4\right)$, although $\mathrm{C}_{a n t}$ is present at lighter densities as well. The highest values are found on the western side of the basin, consistent with subduction in Drake Passage.

\section{Uptake of of anthropogenic carbon}

Our estimate of the net subduction of $\mathrm{C}_{\text {ant }}$ into the ocean interior $(0.42 \mathrm{Pg} \mathrm{C} / \mathrm{yr}$ in 1995 between $35-65^{\circ} \mathrm{S}$ ) is smaller than estimates of the Southern Ocean uptake of $\mathrm{C}_{\text {ant }}$ across the air-sea interface $(\approx 0.8 \mathrm{pg} \mathrm{C} / \mathrm{y})^{9,8}$, underscoring the fact that transfer across the base of the mixed layer is the rate-limiting step in the sequestration of $\mathrm{C}_{\text {ant }}$ in the ocean interior. We compute the total sequestration of $\mathrm{C}_{a n t}$ by net subduction since 1800, by assuming the physical volume transport has not changed over the last two centuries, while accounting for the temporal evolution of $\mathrm{C}_{\text {ant }}$ in the surface mixed layer (see Supplementary Material). We estimate that $23 \pm 10 \mathrm{Pg} \mathrm{C}$ of $\mathrm{C}_{\text {ant }}$ was sequestered between 1800 and 1995. From the GLODAP product ${ }^{18}$, we calculate a total inventory of $25 \pm 5 \mathrm{Pg} \mathrm{C}$ for the Southern Hemisphere between density layers 26.0 and $27.8 \mathrm{~kg} \mathrm{~m}^{-3}$. Our estimate of the net subduction of $\mathrm{C}_{\text {ant }}$ in the Southern Ocean is therefore consistent with the estimated inventory of $\mathrm{C}_{a n t}$ in the ocean interior.

The subduction estimate can be combined with other information to compute an overall budget for $\mathrm{C}_{\text {ant }}$ for comparison with previous studies of the oceanic uptake of $\mathrm{C}_{\text {ant }}$ south of $40^{\circ} \mathrm{S}$. Our net subduction of $\mathrm{C}_{\text {ant }}$ between $65-40^{\circ} \mathrm{S}$ was $0.23 \pm 0.15 \mathrm{Pg}$ $\mathrm{C} / \mathrm{yr}$ in 1995. We estimate the accumulation rate of $\mathrm{C}_{a n t}$ in the mixed layer to be $0.16 \pm 0.16 \mathrm{Pg} \mathrm{C} / \mathrm{yr}$ in 1995, based on measurements of the depth of the mixed layer and the observed rate of increase of dissolved inorganic carbon in the surface layer (see Supplementary Material). Ito and colleagues ${ }^{7}$ used an ocean carbon model to estimate a northward transport across $40^{\circ} \mathrm{S}$ within the mixed layer of $0.16 \mathrm{Pg} \mathrm{C} / \mathrm{yr}$. The sum of these contributions implies a net air-sea uptake of $\mathrm{C}_{\text {ant }}$ of $0.55 \pm 0.31$ 
$\mathrm{Pg} \mathrm{C} / \mathrm{yr}$ between $40^{\circ} \mathrm{S}$ and the the sea ice zone $\left(65^{\circ} \mathrm{S}\right)$. This value is consistent with recent independent estimates of the air-sea exchange of $\mathrm{C}_{\text {ant }}$ south of $40^{\circ} \mathrm{S}$ based on a Green's function approach $(0.8 \pm 0.2 \mathrm{Pg} \mathrm{C} / \mathrm{yr})^{9,8}$, of which 0.1 to $0.2 \mathrm{Pg} \mathrm{C} / \mathrm{yr}$ likely occurs in the sea ice zone, which is not included in our calculation.

$\mathrm{C}_{\text {ant }}$ enters the ocean in specific locations and spreads equatorward along well defined transport pathways, rather than uniformly around the circumpolar belt. Physical transport processes in the Southern Ocean also re-ventilate $\mathrm{C}_{\text {ant }}$ contained in the ocean interior, hence estimates of net sequestration must therefore account for both the subduction and re-ventilation of $\mathrm{C}_{a n t}$. Two often neglected physical mechanisms - eddy transport and lateral induction by the mean flow - make a significant contribution to the magnitude and distribution of the subduction of $\mathrm{C}_{\text {ant }}$ and must be considered when investigating the upper ocean carbon budget. This is shown in a recent modelling study, where lateral induction was an important contributor to the subduction of total carbon ${ }^{25}$. Our analysis demonstrates that the subduction of $\mathrm{C}_{a n t}$ in the Southern Ocean depends on physical variables that are sensitive to climate variability and change, including wind stress, eddy fluxes, surface currents and mixed layer depth. Present climate models vary widely in their ability to represent these properties ${ }^{26,27}$ and therefore the present and future subduction of $\mathrm{C}_{\text {ant }}$. Our results provide an observationally-based estimate of the spatial distribution and magnitude of $\mathrm{C}_{\text {ant }}$ transport from the surface to the ocean interior which can be used to assess models.

\section{Corresponding Author}

Correspondence and requests for materials should be addressed to J.B Sallée (jbsallee@gmail.com)

\section{Acknowledgement}

The comments from $\mathrm{T}$. Ito on an earlier version of this manuscript, and from two anonymous reviewers and N. Gruber have been very valuable and constructive, and have greatly improved this work. The authors would like to acknowledge the funding support of the CSIRO Wealth from Oceans National Research Flagship, the 
Australian Climate Change Science Programme and from the Australian Government's Cooperative Research Centre (CRC) program through the Antarctic Climate and Ecosystems CRC. JBS started this work with the support of a CSIRO Office of the Chief Executive (OCE) Postdoctoral Fellowship.

\section{Author contributions}

J.B.S. directed the analysis of the several datasets used in this study and shared responsibility for writing the manuscript. R.J.M, S.R.R. and A.L. participated in the data analysis and shared responsibility for writing the manuscript. All authors contributed to the final version of the manuscript.

\section{References}

1. Raupach, M., Marland, G., and Ciais, P. Global and regional drivers of accelerating $\mathrm{CO}_{2}$ emissions. Proc. Nat. Acad. Sci. 104(24), 10288-10293 (2007).

2. Le Quéré, C., Raupach, M., Canadell, J., Marland, G., Bopp, L., Ciais, P., Conway, T. J., Doney, S., Feely, R., Foster, P., Friedlingstein, P., Gurney, K., Houghton, J., House, J. I., Hungtingford, C., Levy, P. E., Lomas, M. R., Majkut, J., Metzl, N., Ometto, J. P., Peters, G. P., Prentice, I. C., Randerson, J. T., Running, S., Sarmiento, J. L., Schuster, U., Sitch, S., Takahashi, T., Viovy, N., van der Werf, G. R., and Woodward, F. I. Trends in the sources and sinks of carbon dioxide. Nat. Geosci. 2, 831-836 (2009).

3. Doney, Lindsay, K., Caldeira, K., and Campin, J. Evaluating global ocean carbon models: The importance of realistic physics. Global Biogeochem. Cycles 18(3), GB3017 (2004).

4. Matear, R. Effects of numerical advection schemes and eddy parameterizations on ocean ventilation and oceanic anthropogenic $\mathrm{CO}_{2}$ uptake. Ocean Model. 3, $217-248$ (2001).

5. Sarmiento, J. L., Orr, J. C., and Siegenthaler, U. A perturbation simulation of CO2 uptake in an Ocean General Circulation Model. J. Geophys. Res. 97, 3621-3645 (1992). 
6. Sabine, C., Feely, R., Gruber, N., Key, R., Lee, K., Bullister, J., R, W., Wong, C., Wallace, D., Tilbrook, B., Mollinero, F., Peng, T., Kozry, A., Ono, T., and Rios, A. The oceanic sink for anthropogenic $\mathrm{CO}_{2}$. Science 305, 367-371 (2004).

7. Ito, T., Woloszyn, M., and Mazloff, M. Anthropogenic carbon dioxide transport in the Southern Ocean driven by Ekman flow. Nature 463(7277), 80-83 (2010).

8. Mikaloff Fletcher, S. E., Gruber, N., Jacobson, A. R., Doney, S. C., Dutkiewicz, S., Gerber, M., Follows, M., Joos, F., Lindsay, K., Menemenlis, D., Mouchet, A., Müller, S. A., and Sarmiento, J. L. Inverse estimates of anthropogenic $\mathrm{CO}_{2}$ uptake, transport, and storage by the ocean. Global Biogeochem. Cycles 20(2) (2006).

9. Khatiwala, S., Primeau, F., and Hall, T. Reconstruction of the history of anthropogenic $\mathrm{CO}_{2}$ concentrations in the ocean. Nature 462(7271), 346-349 (2009).

10. Rintoul, S., Hughes, C., and Olbers, D. The Antarctic circumpolar current system. Ocean, Circulation and Climate Academic Press, 271-302 (2001).

11. McNeil, B., Tilbrook, B., and Matear, R. Accumulation and uptake of anthropogenic $\mathrm{CO}_{2}$ in the Southern Ocean, south of Australia between 1968 and 1996. J. Geophys. Res. 106(C12), 31431-31445 (2001).

12. Iudicone, D., Stendardo, I., Aumont, O., Rodgers, K. B., Madec, G., Bopp, L., Mangoni, O., and dAlcala, M. R. Watermasses as a unifying framework for understanding the Southern Ocean carbon cycle. Biogeosciences Discuss. 7, 3392-3451 (2010).

13. Le Quéré, C., Rodenbeck, C., Buitenhuis, E., Conway, T., Langenfelds, R., Gomez, A., Labuschagne, C., Ramonet, M., Nakazawa, T., and Metzl, N. Saturation of the Southern Ocean $\mathrm{CO}_{2}$ sink due to recent climate change. Science 316(5832), 1735 (2007).

14. Lenton, A., Bopp, L., and Matear, R. Strategies for high-latitude northern hemisphere $\mathrm{CO}_{2}$ sampling now and in the future. Deep-Sea Res. (2 Top. Stud. Oceanogr.) $5 \mathbf{6}$, 523-532 (2009). 
15. Lenton, A. and Matear, R. Role of the Southern Annular Mode (SAM) in Southern Ocean $\mathrm{CO}_{2}$ uptake. Global Biogeochem. Cycles 21, GB2016 (2007).

16. McNeil, B., Tilbrook, B., and Matear, R. Seasonal varations in DIC and d13CDIC in the subantarctic zone, South of Australia. Deep-Sea Research accepted (2010).

17. Sallée, J., Speer, K., Rintoul, S., and Wijffels, S. Southern Ocean thermocline ventilation. Journ. of Phys. Ocean. 40(3), 509-529 (2010).

18. Key, R., Kozyr, A., Sabine, C., and Lee, K. A global ocean carbon climatology: Results from Global Data Analysis Project (GLODAP). Global Biogeochem. Cycles 18, GB4031 (2004).

19. Gruber, N., Sarmiento, J. L., and Stocker, T. F. An improved method for detecting anthropogenic CO 2in the oceans. Global Biogeochem. Cycles 10(4), 809-837 (1996).

20. Matsumoto, K. and Gruber, N. How accurate is the estimation of anthropogenic carbon in the ocean? An evaluation of the DC* method. Global Biogeochem. Cycles 19, GB3014 (2005).

21. Alvarez, M., Lo Monaco, C., Tanhua, T., Yool, A., Oschlies, A., Goyet, C., Metzl, N., Touratier, F., Bullister, J., Goyet, C., Metzl, N., Touratier, F., McDonagh, E., and Bryden, H. L. Estimating the storage of anthropogenic carbon in the subtropical Indian Ocean: A comparison of five different approaches OceanRep. Biogeosciences 6, 681-703 (2009).

22. Lo Monaco, C., Goyet, C., Metzl, N., Poisson, A., and Touratier, F. Distribution and inventory of anthropogenic CO2 in the Southern Ocean: comparison of three data-based methods. J. Geophys. Res. 110, C09S02 (2005).

23. Vázquez-Rodríguez, M., Touratier, F., Monaco, C. l., Waugh, D. W., Padin, X. A., Bellerby, R. G. J., Goyet, C., Metzl, N., Ríos, A. F., and Pérez, F. F. Anthropogenic carbon distributions in the Atlantic Ocean: data-based estimates from the Arctic to the Antarctic. Biogeosciences 6(3), 439-451 (2009). 
24. Ito, T., Marshall, J., and Follows, M. What controls the uptake of transient tracers in the Southern Ocean. Global Biogeochem. Cycles 18, GB2021, Jan (2004).

25. Karleskind, P., Levy, M., and Mémery, L. Subduction of carbon, nitrogen, and oxygen in the northeast Atlantic. J. Geophys. Res. 116, C02025 (2011).

26. Downes, S., Bindoff, N., and Rintoul, S. Impact of climate change on the subduction of mode and intermediate water masses in the Southern Ocean. J. Climate 22, 3289-3302 (2009).

27. Russell, J., Dixon, K., Gnanadesikan, A., Stouffer, R., and Toggweiler, J. The Southern Hemisphere westerlies in a warming world: Propping open the door to the deep ocean. J. Climate 19, 6382-6390 (2006).

28. Sallée, J., Speer, K., and Morrow, R. Response of the Antarctic Circumpolar Current to atmospheric variability. J. Climate 21, 3020-3039 (2008).

29. Redi, M. Oceanic isopycnal mixing by coordinate rotation. Journ. of Phys. Ocean. 12, 1154-1158, Jan (1982).

30. Solomon, H. On the representation of isentropic mixing in ocean circulation models. Journ. of Phys. Ocean. 1, 233-234, Jan (1971).

31. Sallée, J., Speer, K., Morrow, R., and Lumpkin, R. An estimate of Lagrangian eddy statistics and diffusion in the mixed layer of the Southern Ocean. Journ. of Marine Res. 66(4), 441-463 (2008).

32. Cisewski, B., Strass, V., and Prandke, H. Upper-ocean vertical mixing in the Antarctic Polar Front Zone. Deep-Sea Res. (2 Top. Stud. Oceanogr.) 52(9-10), 1087-1108 (2005).

33. Lo Monaco, C., Goyet, C., Metzl, N., and Poisson, A. Distribution and inventory of anthropogenic $\mathrm{CO}_{2}$ in the Southern Ocean: Comparison of three data-based methods. J. Geophys. Res. 110, C09S02 (2005). 
34. Lenton, A, Metzl, N., Takahashi, T., Kuchinke, M., Matear, R. J., Roy, T., Sutherland, S. C., Sweeney, C., and Tilbrook, B. The observed evolution of oceanic pCO2 and its drivers over the last two decades. Global Biogeochem. Cycles 26, GB2021 (2012).

35. Matear, R. J., Wong, C. S., and Xie, L. Can CFC-derived water ages be used to determine anthropogenic CO2 concentrations? Global Biogeochemical Cycles (2003).

36. Hall, T. M., Waugh, D. W., Haine, T. W., Robbins, P. E., and Khatiwala, S. Estimates of anthropogenic carbon in the Indian Ocean with allowance for mixing and time-varying air-sea $\mathrm{CO}_{2}$ disequilibrium . Global Biogeochem. Cycles 18, GB1031 (2004).

37. Huang, R. X. The three-dimensional structure of wind-driven gyres: ventilation and subduction. Rev. Geophys. 29((Suppl.), National Report to the IUGG, 1987-1990), 590-609 (1991).

38. Matear, R. and McNeil, B. Decadal accumulation of anthropogenic $\mathrm{CO}_{2}$ in the Southern Ocean: A comparison of CFC-age derived estimates to multiple-linear regression estimates. Global Biogeochem. Cycles 17(4), 1113 (2003).

39. McNeil, B., Matear, R., Key, R., and Bullister, J. Anthropogenic $\mathrm{CO}_{2}$ uptake by the ocean based on the global chlorofluorocarbon data set. Science 299, 235-239 (2003). 


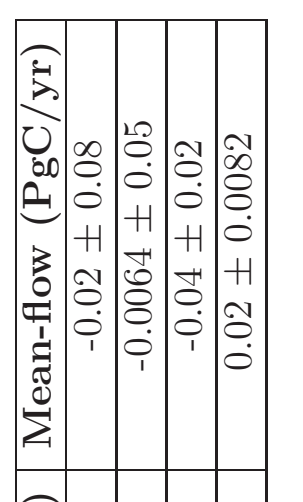

章

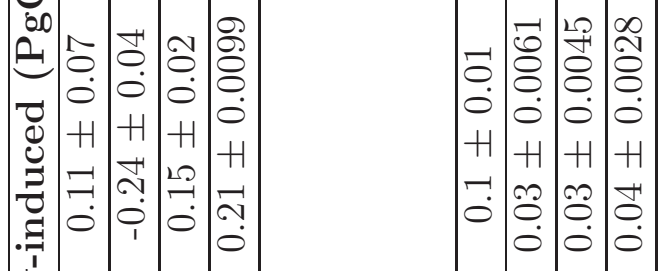

疍

કิ

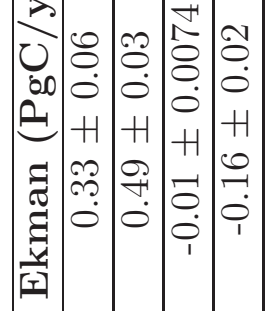

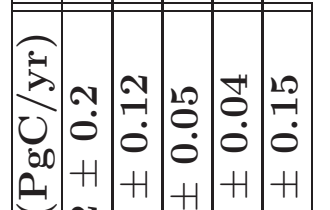

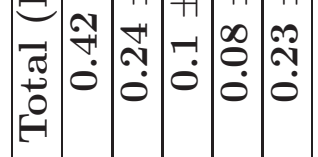

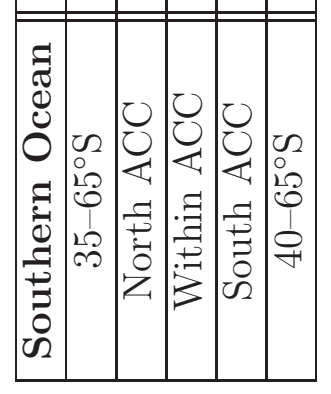

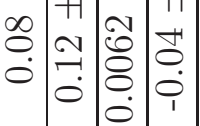

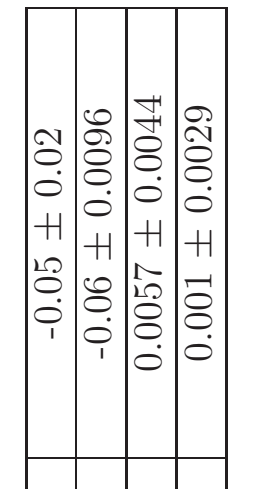

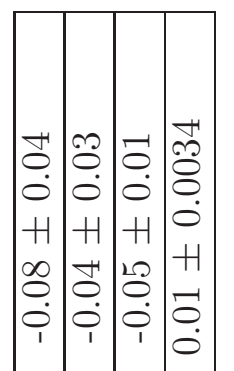

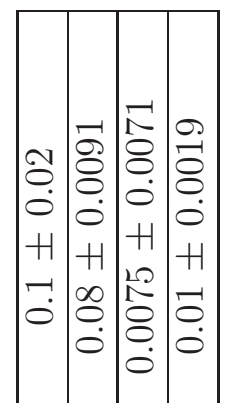

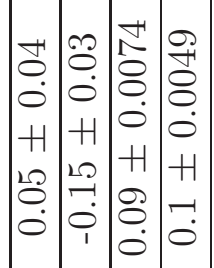

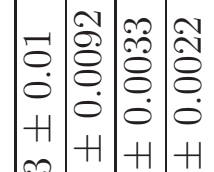

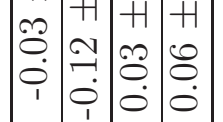

$\begin{array}{lllll}1 & 0 & 0 & 0 \\ & 1 & & \end{array}$

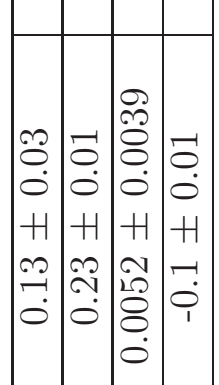

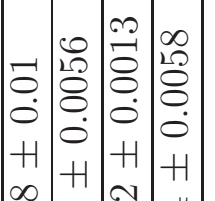

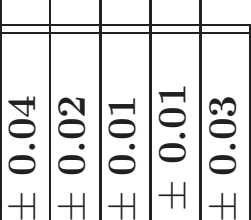

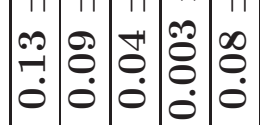

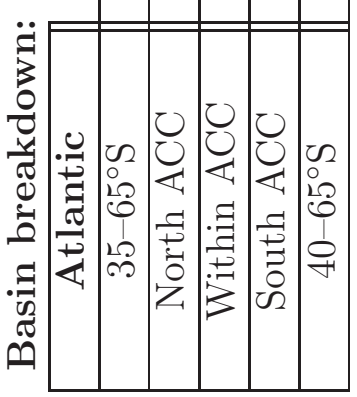

\begin{tabular}{llll}
0 & 0 & 0 & 0 \\
0 & 0 & 0 & 0 \\
\hline & 0 & 0
\end{tabular}

$\mathrm{H}+\mathrm{H} H \mathrm{H}$

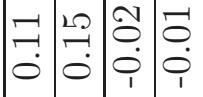

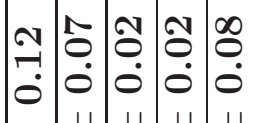

$H+H+H$

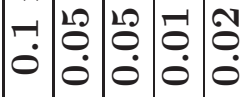

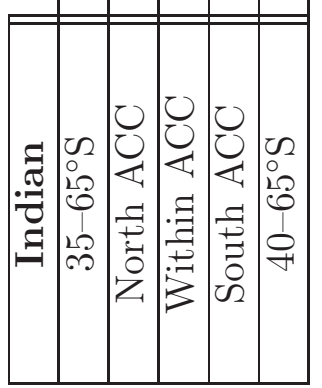

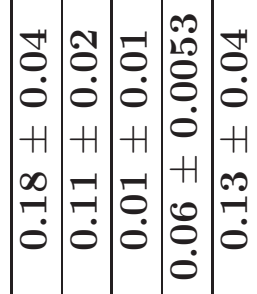

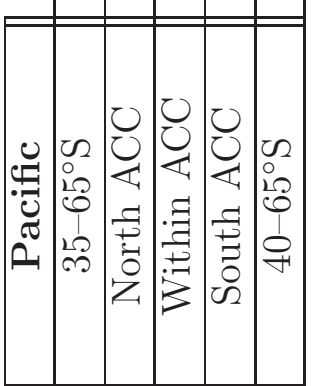

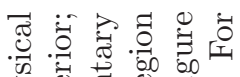

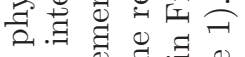

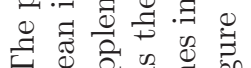

F

10.

$\rightarrow$ 象U品

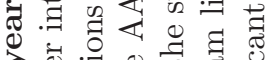

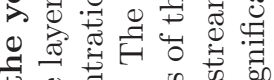

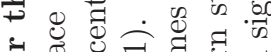

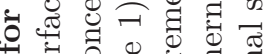

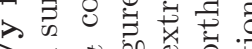

Oิ

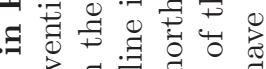

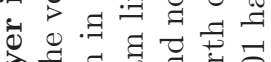

ब

ن :

㐘

क 记

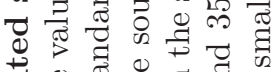

匹

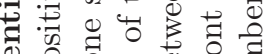

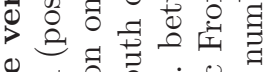

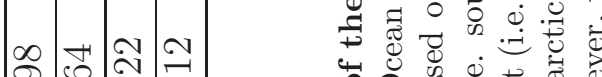

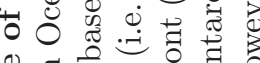

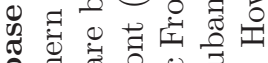

율

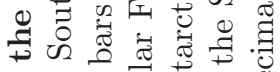

की

วิ山े

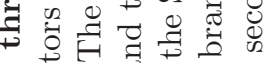

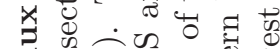

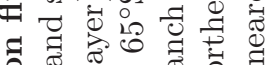

象 0

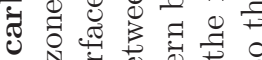

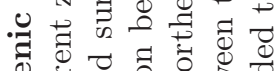

$D_{0} 0.0$

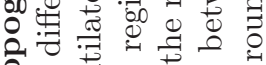

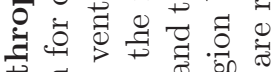

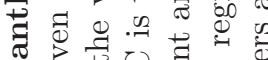

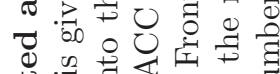

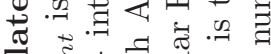

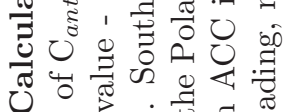

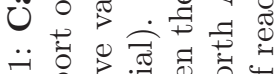

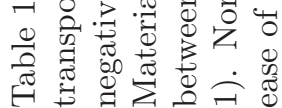


(a)

(b)
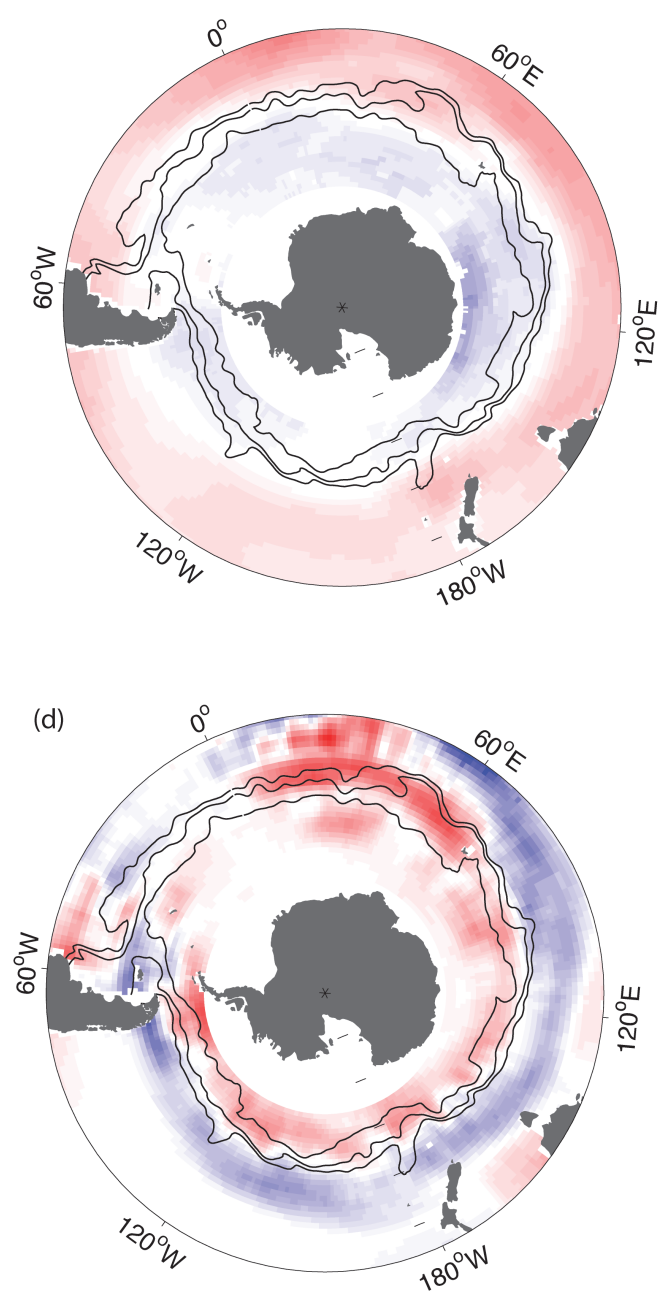

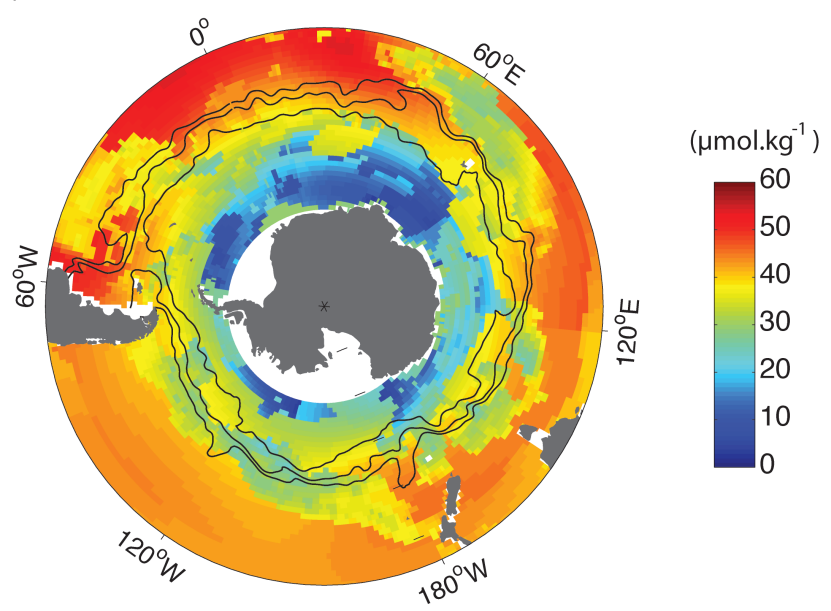

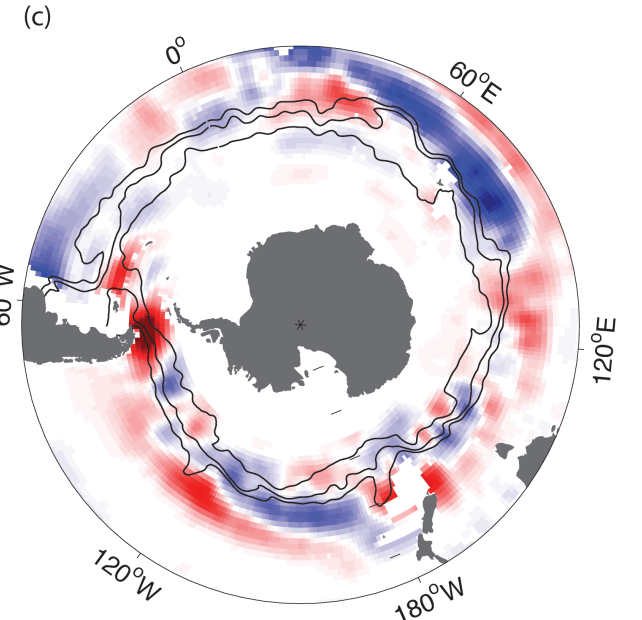

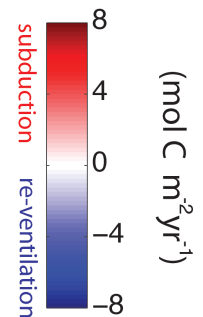

Figure 1: Anthropogenic $\mathbf{C O}_{2}$ subduction into the ocean interior. (a) Annual mean anthropogenic carbon at the base of the winter mixed layer from GLODAP ${ }^{18}$. The $\mathrm{C}_{\text {ant }}$ transport out of $(+)$ and into (-) the ventilated surface layer for (b) Ekman, (c) mean-flow, (d) eddy-induced, and (e) total transports. The thin black lines show the mean position of the three main ACC fronts ${ }^{28}$ where the most northern and southern lines denotes the boundary of the ACC region referred to in Table 1.

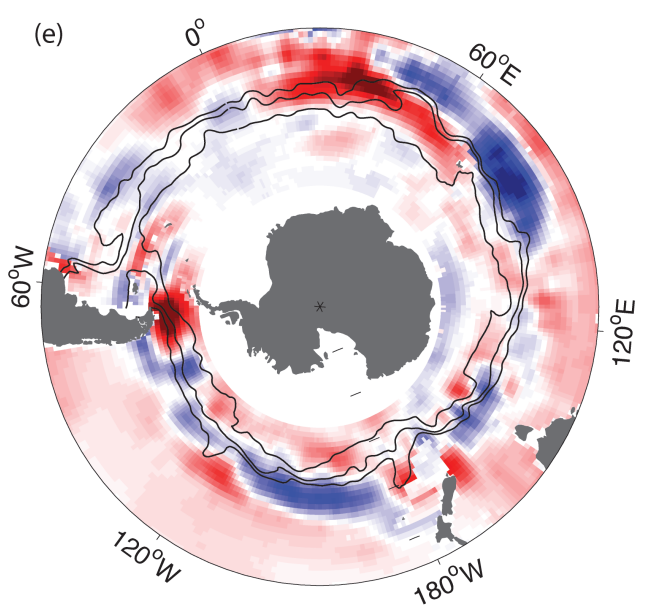


(a)

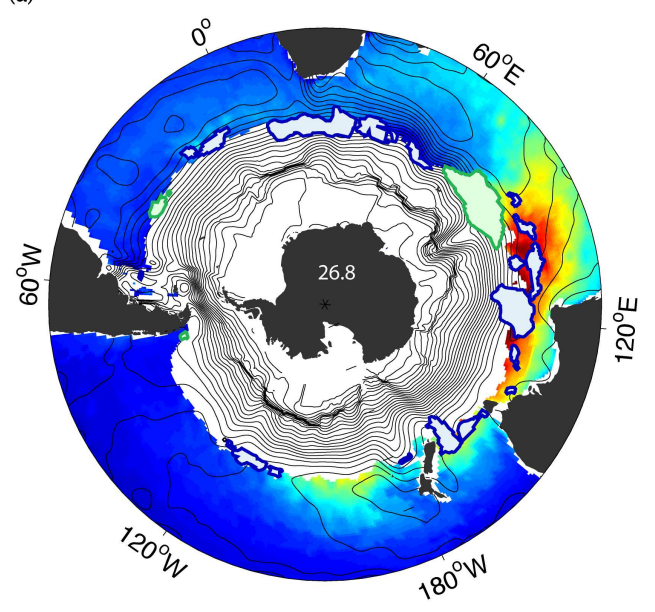

(c)

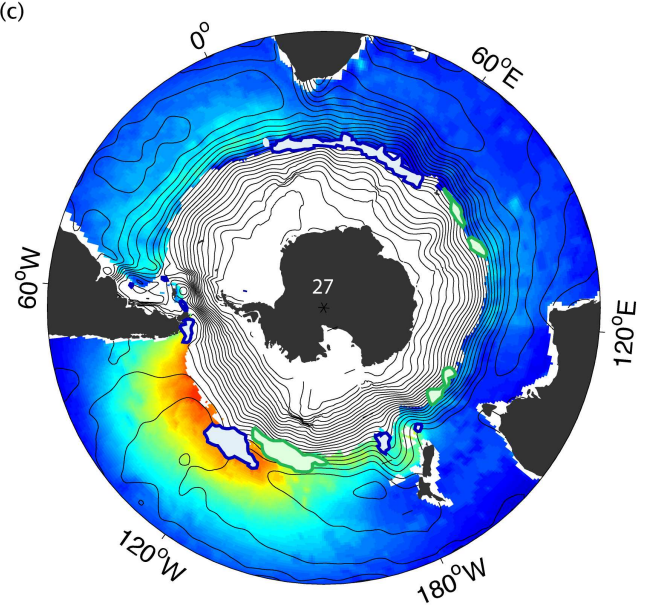

(b)

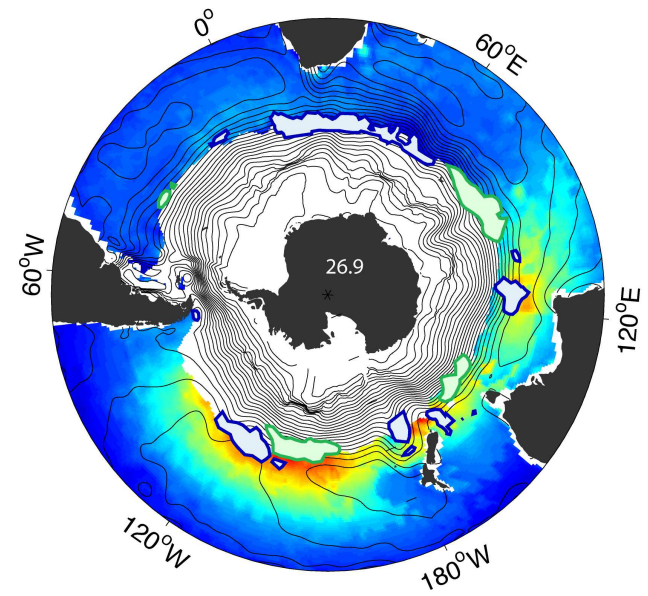

(d)

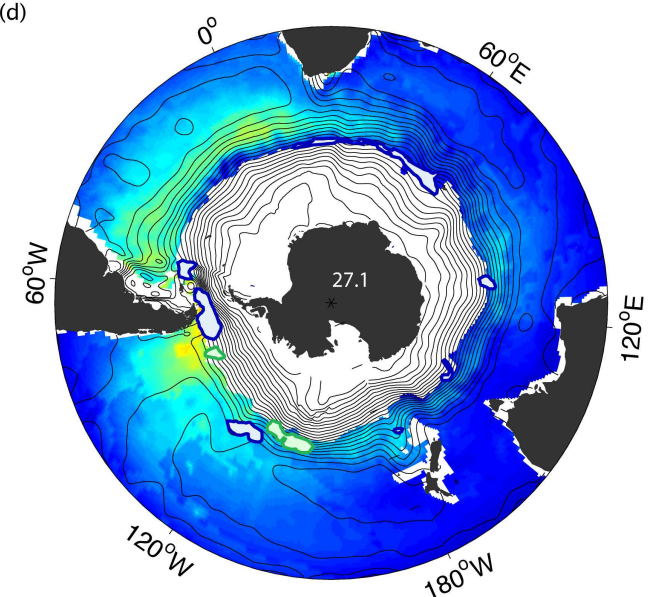

(e)

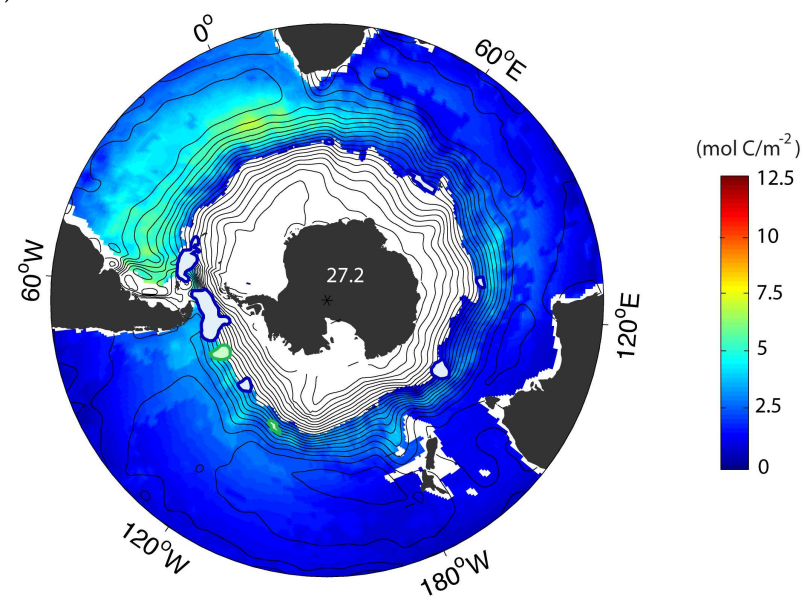

Figure 2: Anthropogenic $\mathbf{C O}_{2}$ inventory versus subduction pattern. The $\mathrm{C}_{\text {ant }}$ inventory on selected isopycnal surfaces $\left( \pm 0.05 \sigma_{\theta}\right)$ : a) 26.8 , b) 26.9 , c) 27 , d) 27.1 e) 27.2 . The black lines are the Montgomery stream lines indicating the approximate geostrophic circulation on each isopycnal. White patches highlight with a thick blue line are regions of subduction maxima. White patches with a thick green line are regions of re-ventilation maxima. 


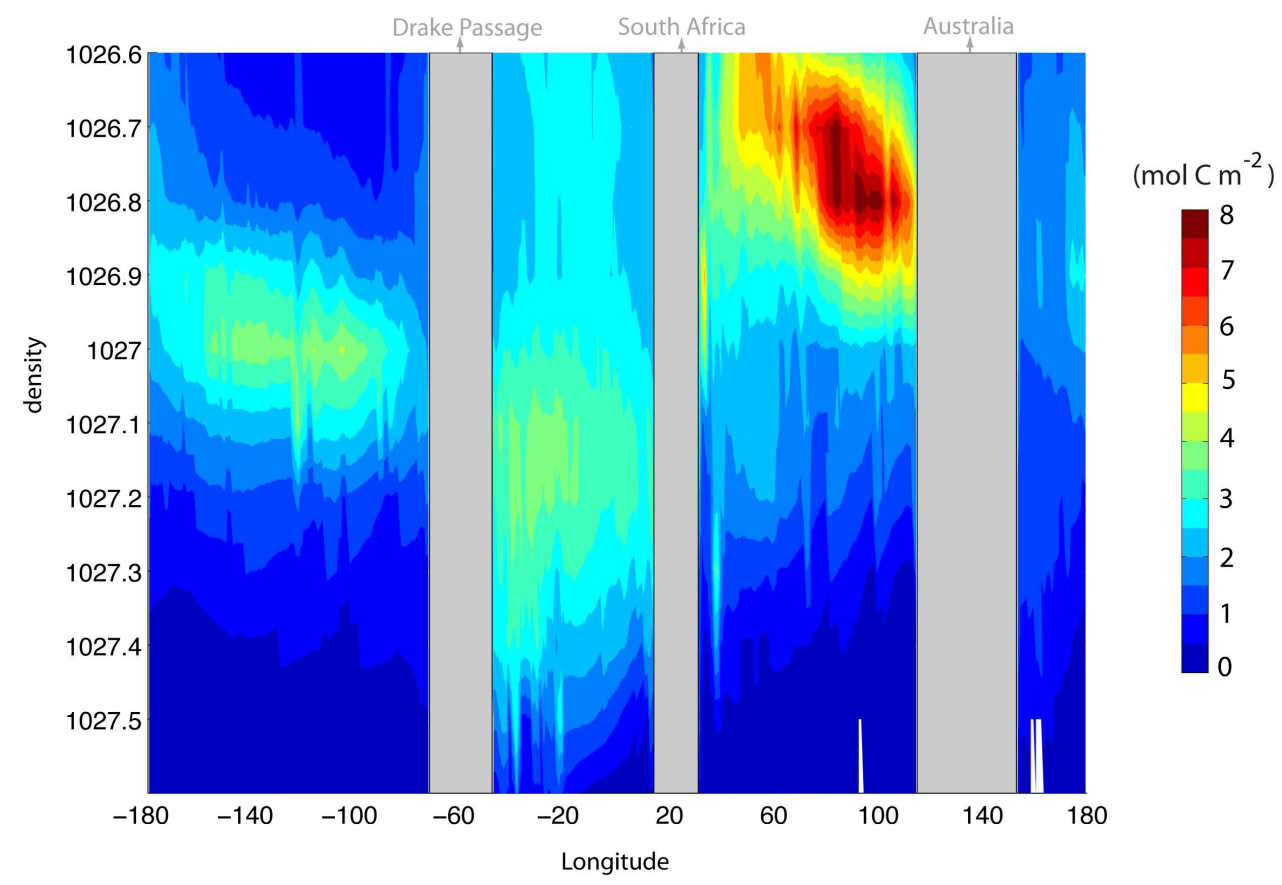

Figure 3: Vertical structure of anthropogenic $\mathrm{CO}_{2}$ inventory at $30^{\circ} \mathrm{S}$. Circumpolar section of $\mathrm{C}_{\text {ant }}$ inventory at $30^{\circ} \mathrm{S}$ along potential density surfaces (inventory within $\pm 0.05 \sigma_{\theta}$ ). 


\section{Methods}

We define the physical transport of anthropogenic $\mathrm{CO}_{2}\left(\mathrm{C}_{a n t}\right)$ out of the upper ocean into the ocean interior as the rate by which $\mathrm{C}_{\text {ant }}$ is injected from the seasonal thermocline (i.e. the water above the base of the winter mixed layer, which has been in recent contact with the atmosphere) into the ocean interior ${ }^{17}$. This transport is associated with the $\mathrm{C}_{\text {ant }}$ budget above the base of the winter mixed-layer:

$$
\frac{\partial C_{a n t}}{\partial t}+\nabla \cdot\left[T_{\text {res }}(t) \cdot C_{\text {ant }}(t)\right]=\mathcal{C}_{\text {uptake }},
$$

which becomes after time-averaging:

$$
\underbrace{\overline{C_{\text {ant }}} \cdot \bar{S}+\mathcal{M}_{\text {base SL }}}_{\overline{C_{\text {subduction }}}}=\overline{\mathcal{C}_{\text {uptake }}}-\overline{\mathcal{C}_{\text {acc }}}-\underbrace{\left(\overline{T_{\text {res }}} \cdot \nabla_{h} \overline{C_{a n t}}+\mathcal{M}_{S L}\right)}_{\text {horizontal transport }},
$$

where $\overline{(.)}$ refers to the annual mean; $\mathrm{T}_{\text {res }}$ is the transport above the base of the winter mixed-layer resulting from the Ekman, mean, and eddy-induced flow; $\bar{S}=\nabla_{h} \overline{T_{\text {res }}}$ is the annual mean subduction ${ }^{17} ; \overline{\mathcal{C}_{\text {uptake }}}$ is the annual mean air-sea flux of $\mathrm{C}_{a n t} ; \overline{\mathcal{C}_{a c c}}$ is the annual mean $\mathrm{C}_{\text {ant }}$ accumulation in the surface layer; $\mathcal{M}_{\text {base } S L}$ is the mixing term operating at the base of the surface layer; and $\mathcal{M}_{S L}$ is the horizontal mixing operating within the mixed layer.

We define subduction as the transport of $\mathrm{C}_{a n t}$ out of the ventilated surface layer into the ocean interior and re-ventilation as the transport of $\mathrm{C}_{a n t}$ from the ocean interior back into the ventilated surface layer. This two-way transfer of $\mathrm{C}_{\text {ant }}$ across the base of the winter mixed layer, $C_{\text {subduction }}(t)$, can occur all year round and is the result of the divergence of $\mathrm{C}_{a n t}$ transport within the ventilated layer and mixing processes at the base of the surface layer (lhs of Equation 1b).

Our calculation is applied in the Southern Ocean, north of the marginal seaice zone where the Argo coverage provides sufficient observations. The estimates of annual-mean water mass injection into the ocean interior $(\bar{S})$ agree with the climatological potential vorticity structure of the ocean interior ${ }^{17}$.

The mixing term in the lhs of Equation $1 b$ includes a vertical mixing term at the base of the surface layer, and an along-isopycnal eddy flux ${ }^{29,30}$ :

$$
\mathcal{M}_{\text {base } S L}=\int_{\text {surface-layer }}\left(\frac{\partial}{\partial z} \kappa_{z} \frac{\partial C}{\partial z}+\nabla_{\gamma} \cdot \kappa_{\gamma} \nabla_{\gamma} C\right) \cdot d z
$$


where $\kappa_{z}$ and $\kappa_{\gamma}$ are the vertical and along-isopycnal mixing coefficients, and $\nabla_{\gamma}$ and $\left(\nabla_{\gamma} \cdot\right)$ are the along-isopycnal gradient and divergence operator. Because $\mathrm{C}_{\text {ant }}$ is well mixed in the surface layer (i.e. $\partial C / \partial z=\nabla_{\gamma} \mathrm{C}=0$ ), the mixing terms act only at the base of the surface-layer. An upper bound estimate of the magnitude of the mixing terms can be made using large mixing coefficients ${ }^{31,32}\left(\kappa_{z} \alpha 10^{-4} \mathrm{~m}^{2}\right.$ $\mathrm{s}^{-1}$ and $\left.\kappa_{\gamma} \alpha 10^{4} \mathrm{~m}^{2} \mathrm{~s}^{-1}\right)$ and conservative values of the gradient of $\mathrm{C}_{\text {ant }}(10 \mu \mathrm{mol}$ $\mathrm{kg}^{-1}$ over $50 \mathrm{~m}$ depth, and $10 \mu \mathrm{mol} \mathrm{kg}^{-1}$ over $1^{\circ}$ on isopycnals). Therefore, vertical mixing term is estimated to be $10^{-17} \mathrm{Pg} \mathrm{C} \mathrm{m}^{-2} \mathrm{yr}^{-1}$, and the isopycnal mixing term to be $10^{-15} \mathrm{Pg} \mathrm{C} \mathrm{m}{ }^{-2} \mathrm{yr}^{-1}$, which are two orders of magnitude smaller than the other terms (Figure 1) and are neglected in the remainder of the study.

The annual mean carbon subduction is therefore composed of three main components: a wind-induced Ekman transport; a mean geostrophic transport; and an eddy-induced transport. We compute these fluxes as follow ${ }^{17}$ :

$$
\overline{C_{\text {subduction }}}=\left(\overline{S_{e k}} \cdot \bar{C}+\overline{S_{\text {geo }}} \cdot \bar{C}+\overline{S_{\text {eddy }}} \cdot \bar{C}\right)
$$

where:

$$
\begin{gathered}
\overline{S_{e k}}=\operatorname{curl}\left(\frac{\bar{\tau}}{\rho f}\right), \\
\overline{S_{g e o}}=\nabla \cdot\left(\overline{\mathbf{u}_{\text {geo }}} \cdot \overline{H_{\max }}\right), \\
\overline{S_{\text {eddy }}}=\nabla \cdot[\kappa \cdot \overline{\mathbf{s}}]_{z=H_{\max }} .
\end{gathered}
$$

$H_{\text {max }}$ is the depth of the ventilated layer (i.e. winter mixed layer depth) ${ }^{17} ; \tau$ is the wind stress estimated from satellite winds; $\rho$ is the density of seawater; $u_{\text {geo }}$ is the geostrophic velocity estimated from climatology strengthened with Argo data; $\kappa$ is the mesoscale eddy diffusion intensity estimated from surface drifter trajectories ${ }^{31}$; and $s$ is the slope of isopycnal (i.e. $\bar{s}=\nabla \bar{\rho} / \overline{\rho_{z}}$ ). We compute Eqn. 3 with an upwindweighted scheme, which accounts for the dependence of the carbon transport on the sign of subduction: transport into the mixed layer from the interior uses the $\mathrm{C}_{\text {ant }}$ concentration $10 \mathrm{~m}$ below $H_{\max }$ and transport from the mixed layer to the interior uses the $\mathrm{C}_{\text {ant }}$ concentration in the mixed layer. 